\title{
Response of Escherichia coli containing mycobacterial carotene genes to UV radiation
}

\author{
Mohamed Houssaini-Iraqui, ${ }^{1 *}$ Naima Khamlichi, ${ }^{1}$ Jamal El Yamani, ${ }^{1}$ and Nalin Rastogi ${ }^{2}$ \\ ${ }^{1}$ Biotechnology Laboratory, Sidi Mohammed Ben Abdellah University, FST, P.O. Box 2202, Fez, Morocco \\ ${ }^{2}$ Tuberculosis and Mycobacteria unit, Pasteur Institut, P.O. Box 484, Pointe a Pitre Guadeloupe, France
}

\begin{abstract}
The plasmid pC5, which encodes biogenesis of lycopene in Mycobacterium aurum $A^{+}$, was partially digested by restriction endonucleases and generated fragments were cloned. After transformation of Escherichia coli (colorless bacteria) with the plasmids so constructed, seven orange clones were detected and found to carry the same recombinant plasmid (pC51). E. coli cells containing this plasmid synthesize neurosporene and lycopene, and were more resistant to ultraviolet irradiation than nonpigmented strain.
\end{abstract}

\section{INTRODUCTION}

Carotenoid pigments are largely distributed in nature. They are present in all of the photosynthetic organisms as well as in some bacteria, fungi, and yeast [1]. Two major biological roles have been assigned to carotenoids in plants and prokaryotes. In photosynthetic organisms, these pigments are involved in trapping light energy. A more general role applicable to both photosynthetic and non-photosynthetic cell, is protection from photodynamic action [1]. Genes controlling the synthesis of these pigments have been studied in several organisms such as Erwinia species [2-4], Mycobacterium aurum $A^{+}[5,6]$, Arabidopsis $[7,8]$, Xantophyllomyces dendrorhous [9] and Brevibacterium linens [10].

The synthesis of lycopene can be divided into two stages: the synthesis of phytoene and its desaturation (dehydrogenation) [11]. The precursor of carotene is isopentenyl pyrophosphate (IPP, $\mathrm{C}_{5}$ ) obtained from mevalonic acid. IPP is converted to farnesyl pyrophosphate (FPP, $\mathrm{C}_{15}$ ). The condensation of IPP and FPP are required for the synthesis of the geranylgeranyl pyrophosphate (GGPP, $\mathrm{C}_{20}$ ). This reaction is catalyzed by GGPP synthase. The gene coding for this enzyme has been cloned in several species $[2,4,6,12]$. The dimerization of GGPP produces prephytoene pyrphosphate (PPPP, $\left.\mathrm{C}_{40}\right)$ that is converted into phytoene $\left(\mathrm{C}_{40}\right.$ colorless hydrocarbon). These reactions are catalysed by phytoene synthase [13]. The gene coding for this enzyme was cloned in Erwinia herbicola and leads to the synthesis phytoene from GGPP in Escherichia coli $[2,4,14]$. Four sequential desaturations are required to convert phytoene into lycopene by phytoene desaturase (dehydrogenase); the intermediate precursors are successively phytofluene, $\zeta$-carotene and neurosporene (Figure 1) $[11,13]$. In non-photosynthetic organisms such as Erwinia herbicola and Erwinia uredorora, phytoene desaturase is the product of a single gene that is capable to express in $E$. coli $[2,4,13,15]$.

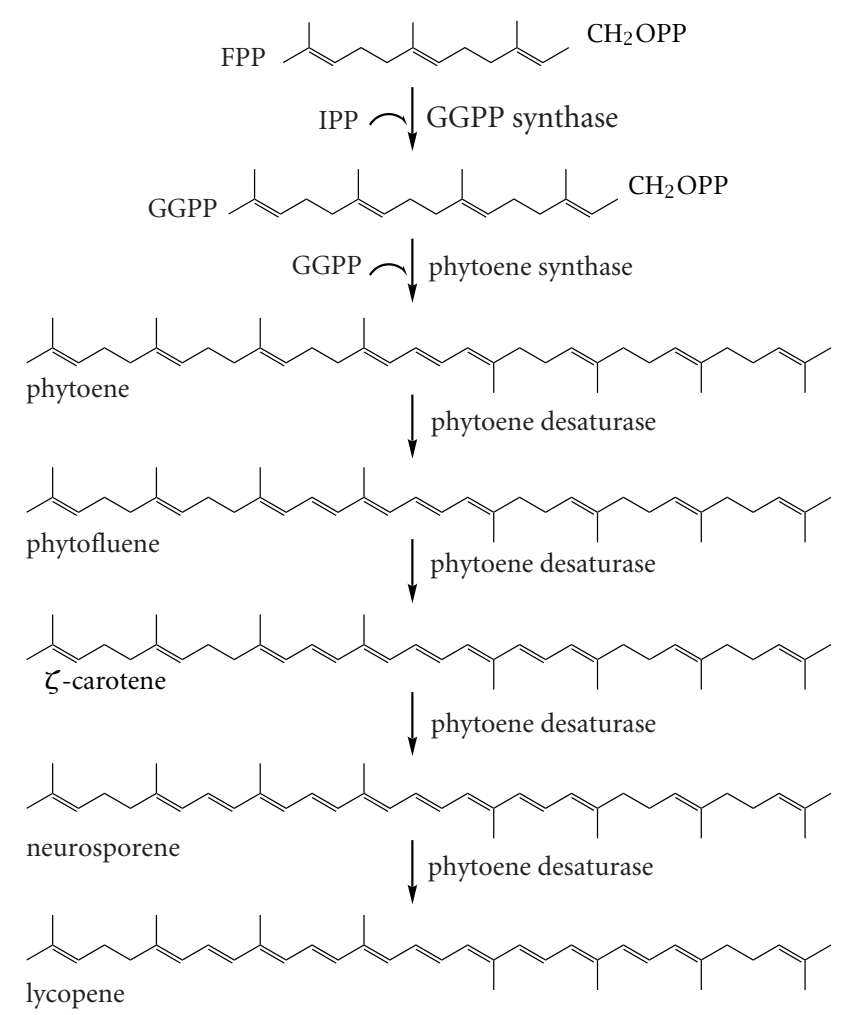

Figure 1: Pathway of lycopene biosynthesis in non-photosynthetic bacteria $[2,4,13,14]$. Symbols; IPP, isopentenyl pyrophosphate; FPP, farnesyl pyrophosphate; GGPP, geranylgeranyl pyrophosphate.

Oxidative stress is recognized as one of the majors contributors of increased risk of cancer. Considerable evidence suggests that lycopene has significant antioxidant potential and may play a role in preventing cancer and coronary heart disease $[16,17]$. For the purpose of investigating beneficial 
effect of this pigment, we decided to express in E. coli the mycobacterial genes responsible for its synthesis, and to study its evaluation as protectant against UV radiation.

The pC5 plasmid was previously isolated from the wildtype Mycobacterium aurum $A^{+}$(yellow-orange phenotype) genomic library [18]. This plasmid contains an insert of about $8.8 \mathrm{~kb}$ controlling the biogenesis of lycopene in colorless A11 mutant of $M$. aurum, which naturally synthesizes phytoene $[18,19]$. We report here the first molecular cloning and expression in E. coli of clustered mycobacterial genes coding for lycopene synthesis, and further discuss the role of the carotenes in protection against ultraviolet irradiation.

\section{MATERIALS AND METHODS}

\section{Plasmids and strain}

The cloning vector used was pHLD69 (6.3 kb), containing pUC19, the Ori R of pAL5000, and the $\mathrm{Kan}^{\mathrm{r}}$ gene [5]. The second plasmid used in this work was pC5 that was previously isolated from the Mycobacterium aurum $A^{+}$genomic bank. This vector which in addition to pHLD69 vector $(6,3 \mathrm{~kb})$ contains an insert of about $8.8 \mathrm{~kb}$ controlling the biogenesis of lycopene in colorless M. aurum A11 and the buff-colored Mycobacterium smegmatis $\mathrm{MC}^{2}-155$ [18]. E. coli $\mathrm{DH} 5 \alpha\left(\mathrm{kan}^{\mathrm{s}}, \mathrm{lac}^{-}\right)$was used as a host for the plasmids. This bacterium was grown in Luria Bertoni (LB), and their transformants were selected with $50 \mu \mathrm{g} / \mathrm{ml}$ of kanamycin.

\section{Isolation of pC51 plasmid coding for lycopene in E. coli}

The plasmid pC5 was partially digested by the restriction endonucleases Sau 3A, Sph I or Pst I. The generated fragments were ligated respectively in the pHLD69 vector digested with Bam HI, Sph I, or Pst I. The ligation mixtures were used to transform E. coli $\mathrm{DH} 5 \alpha$ and the transformants selected on LB agar containing $50 \mu \mathrm{g} / \mathrm{ml}$ of kanamycin and $0.4 \mathrm{mM}$ of isopropyl- $\beta$-D-thiogalacto-pyranoside (IPTG). Seven pigmented transformants were cloned, and their plasmid DNAs were extracted and analysed by some restriction endonuclease. This experiment showed that these clones harbored the same recombinant plasmid designated pC51. The methods used for cloning, amplification and DNA extraction were applied as previously described [20].

\section{Physical map of pC51}

The plasmids pC51 and pC5 were digested with restriction endonuclease Pst I, Sph I, Bam HI, EcoR I, and Kpn I. The generated fragments were compared and aligned on the physical map of pC5 previously determined [19].

\section{Identification and quantitative determination of pigments}

The pC51 vector was used to transform E. coli. The transformants were selected on LB agar containing kanamycin and IPTG as described above. The harvest cells were extracted several times with chloroform/methanol $(1: 1, \mathrm{v} / \mathrm{v})$. The extracts were dried in vacuo and the colored residues were dissolved in pure acetone. The cloudy acetone extracts were refrigerated at $4^{\circ} \mathrm{C}$ for several hours and then clarified by centrifugation. The colored supernatants were dried and redissolved in methanolpetroleum ether $(1: 1, \mathrm{v} / \mathrm{v})$, the mixtures were vigorously vortexed and the pigments were separated by thin-layer chromatography on silica gel $60 \mathrm{~A}$ (Whatman). The solvent used was $2 \%(\mathrm{v} / \mathrm{v})$ acetone in hexane. The presence of the colourless precursors (phytoene, phytofluene) was examined by fluorescence in UV light; the colored spots were determined visually. The individual zones on the chromatogram were separated and eluted with the mixture of acetone-ethanol $(1: 1, \mathrm{v} / \mathrm{v})$. After evaporation, the residues were dissolved in suitable pure solvents and spectra were measured. The pigments were identified by comparison with published spectra [21]. Lycopene (all-trans, Sigma Chemical Company, St. Louis, Missouri) was used for comparative purpose. Quantitative determinations of the carotenoid fractions were performed spectrometrically in petroleum ether using the following extinction coefficient $E$ values: 2900 for neurosporene, and 3400 for lycopene. All procedures were carried out in darkness whenever possible.

\section{Ultraviolet irradiation}

Ten orange colonies of E. coli containing pC51 and cultivated in presence of IPTG and kanamycin on LB-agar at $37^{\circ} \mathrm{C}$ for $60 \mathrm{~h}$ were suspended in LB medium and then diluted to have $10^{4}$ cells $/ \mathrm{ml}$. For each time of exposure to ultraviolet light, $100 \mu \mathrm{l}$ of diluted culture were plated into Petri dishes containing $25 \mathrm{ml}$ of LB-agar medium and then exposed to UV radiation. Count of colonies was made after $20 \mathrm{~h}$ of incubation. The same method was used for the controls: E. coli and E. coli transformed by pHLD69. For all strains used and for each time of exposure, the given value represents the mean of two or three experiments. Irradiation was made by an ultraviolet lamp (6 W-254 nm tube; Vilber Lourmat, French) from the distance of 14,50 , or $77 \mathrm{~cm}$. Time of exposure for these distances were respectively; $0,2,4,5,6,7,8,9,10,11$ seconds; $0,5,10,15,25,35,45,50,55$ seconds; and $0,5,10$, $15,25,35,45,55,65,75,90,110,120,130$ seconds. A petri dish containing LB-agar medium was exposed to UV light for $15 \mathrm{mn}$ at a distance of $50 \mathrm{~cm}$, and then inoculated with the $E$. coli strain. After incubation, the number of clones was found to be identical to that found in parallel controls not exposed to UV light, showing that the medium did not deteriorate following UV exposition.

\section{RESULTS}

\section{Obtaining of orange-pigmented colonies of E. coli}

Clones of E. coli containing plasmid pC5 (Figure 2) did not form any carotene $[5,18]$. This plasmid was partially digested by the restriction endonucleases Sau 3A, Sph I, or Pst I. The fragments generated were cloned, respectively, in the pHLD69 vector digested with Bam HI or Sph I or Pst I. The three ligation mixtures were used to transform $E$. coli (nonpigmented bacterium). After transformation, bacteria were transferred to solid media containing IPTG. All the clones obtained by the cloning with the enzymes Bam HI or Sph I were nonpigmented. Amongst those obtained 

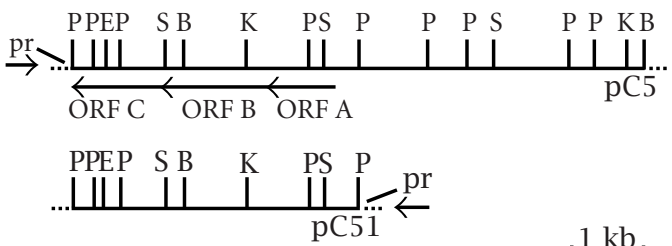

$1 \mathrm{~kb}$

FIgure 2: Physical map of pC51 plasmid DNA and its alignment with the pC5 restriction map. Dots represent the plasmid vector pHLD69. Symbol; pr: lacZ promoter, and the arrow indicates its orientation. Restriction endonuclease sites are abbreviated as follows; B, BamHI; E, EcoR I; K, Kpn I; P, Pst I; S, Sph I. The ORFs $\mathrm{A}, \mathrm{B}$, and $\mathrm{C}$ were identified on the basis of sequence homologies, and encode for GGPP synthase, phytoene desaturase and phytoene synthase, respectively [6].

by the cloning with Pst I, seven orange clones were detected and cloned. Plasmids DNAs were prepared from these orange colonies and subjected to Pst I, Sph I, Bam HI digestion. This experiment (results not shown) showed that all the clones harbored the same recombinant plasmid designated pC51 containing an insert of $4.42 \mathrm{~kb}$ (Figure 2). Further, E. coli was transformed by pC51, and all the clones obtained after $60 \mathrm{~h}$ of incubation at $37^{\circ} \mathrm{C}$ were orange-colored. It was therefore concluded that the plasmid pC51 is responsible for the orange pigmentation of the bacteria.

\section{Analysis of carotenoids}

Carotenoid pigments from E. coli containing pC51 were extracted and separated by preparative thin-layer chromatography (TLC) and two carotenes were detected; the major red carotenoid was purified and proved to be identical to lycopene by its visible spectrum.

Indeed, this spectrum was similar to both the commercial lycopene and also the lycopene extracted from the wild-type M. aurum $A^{+}$(Figure 3). The identity of this major pigment was also verified by cochromatography with authentic sample. E. coli harboring plasmid pC51 accumulated large amounts of lycopene; its yield was $0.25 \mu \mathrm{g} / \mathrm{mg}$ dry wt after $60 \mathrm{~h}$ of incubation at $37^{\circ} \mathrm{C}$ (Figure 3). Furthermore, a yellow pigment was isolated and was confirmed to be neurosporene by its spectrum (Figure 3). This pigment is present in similar amount as compared to lycopene as it is converted to lycopene (Figure 3). However, phytoene, phytofluene and $\zeta$-carotene (Figure 1) were not detected in extract of E. coli transformed by $\mathrm{pC} 51$.

\section{Resistance to ultraviolet irradiation of E. coli ( $p$ C51)}

To analyze the role of the carotenoids in protection against UV irradiation, E. coli (pC51) was exposed to UV rays as described in materials and methods section. Briefly, strains were incubated at $37^{\circ} \mathrm{C}$ for $60 \mathrm{~h}$ prior to UV exposure. As indicated in Figure 3, this incubation time was intentionally chosen as it permits the maximal synthesis of the carotenes. At a distance of 14 or $50 \mathrm{~cm}$ from the UV lamp, all strains had the same sensitivity to the UV light (Figure 4). However, at a distance of $77 \mathrm{~cm}$, cells of

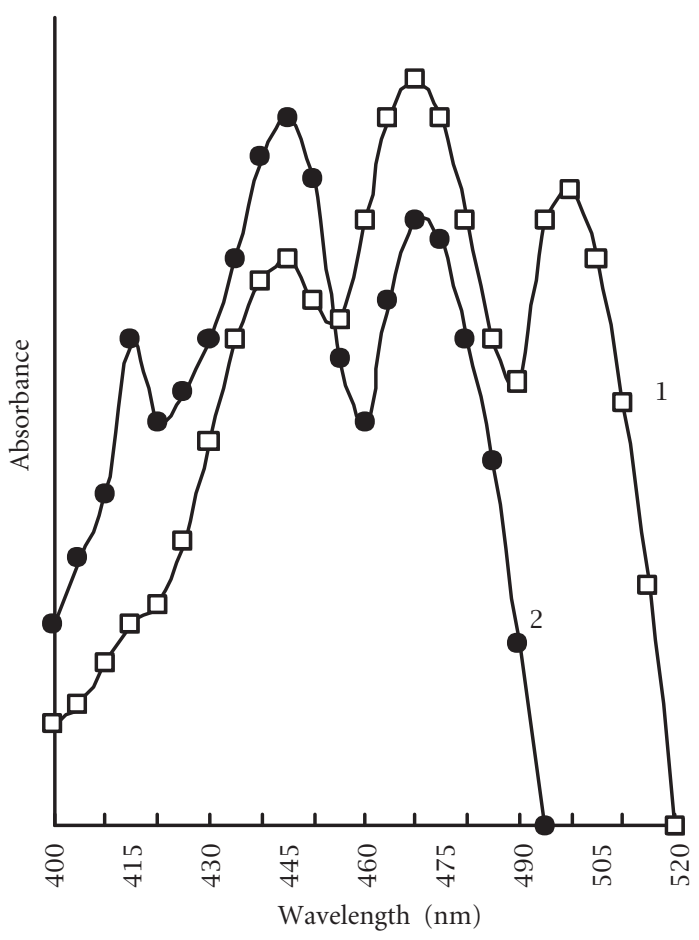

(a)

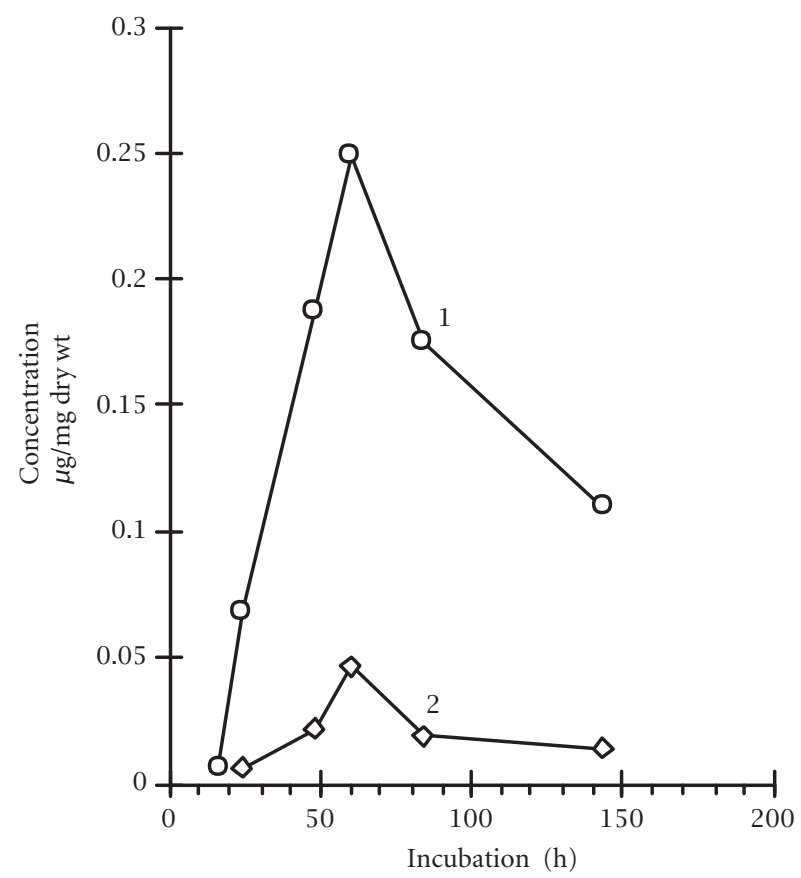

(b)

FIgURE 3: The spectrum (a) and concentrations (b) of pigments extracted from E. coli containing pC51. Symbols; 1, lycopene; 2, neurosporene.

E. coli (pC51) were more resistant than the parallel controls (E. coli and E. coli containing pHLD69; Figure 4). This result indicates that the carotenoid pigments are able 
to prevent the lethal action of UV irradiation on bacterial cells.

\section{DISCUSSION}

The plasmid pC51 was isolated by subcloning the vector pC5 into the plasmid pHLD69. Clones of E. coli containing pC51 were orange, whereas E. coli harboring pC5 was not pigmented and did not form any carotene. This result suggests that the insert of pC51 was transcribed from the lac $Z$ promoter (Figure 2). This insertion permits the development of a new colored marker for use in E. coli and mycobacteria.

It is established that the synthesize of lycopene is the result of stepwise desaturation of phytoene resulting successively in the formation of phytofluene, $\boldsymbol{\zeta}$-carotene, neurosporene, and lycopene (Figure 1) $[11,13]$. We previously showed that plasmid pC5 controls the biogenesis of lycopene $[18,19]$. This result was determined by complementation experiments that showed the formation of lycopene by colorless Mycobacterium aurum A11, which synthesizes phytoene [19]. However, these experiences were not conclusive as to whether the pC5 plasmid contained the genes responsible for GGPP and phytoene production (Figure 1). The use of a heterologous system such as E. coli (no mycobacterial host) may give an answer to this question. Indeed, cells of E. coli do not normally synthesize phytoene or other carotenoids, but they do produce FPP $[14,22]$, which is the precursor of GGPP (Figure 1). E. coli harboring pC51 produced lycopene, demonstrating that this plasmid codes for three enzymes: GGPP synthase, phytoene synthase, and phytoene desaturase. These enzymes are required to synthesize the lycopene from FPP in this bacteria (Figure 1). These results are in agreement with recent investigations concerning the sequencing of a DNA fragment of the plasmid $\mathrm{pC} 1[5,18,19]$, that contains the eight genes that intervene in synthesis of carotenes in $M$. $a u$ rum $A^{+}$[6]. The plasmids pC1 and pC5 share a homologous sequence of $6.5 \mathrm{~kb}$ [18], and its sequencing showed that it did contain the genes coding for GGPP synthase, phytoene synthase, and phytoene desaturase. These genes were identified on the basis of sequence homologies [6]. A comparison of the results from this investigation with those obtained in the present study shows that the plasmid pC51 contains the three genes mentioned above (Figure 2).

Phytoene, phytofluene, and $\zeta$-carotene were not detected in extracts of $E$. coli transformed by pC51, suggesting that these carotenes were rapidly converted into lycopene (Figure 1). This result was in line with previous findings with extracts of $M$. aurum $A^{+}$and $M$. aurum $\mathrm{NgR9}$, which only contain small amounts of neurosporene but not other precursors of lycopene [23]. It is now established that the intermediate precursors in the biosynthesis of the carotenoids are rapidly and sequentially converted. This is based on kinetic data in mycobacteria that form the carotenoids by induction, and from kinetic data on the accumulation of the carotenoids after removal of chemical inhibitors [24]. In all cases, the end-products of carotenogenesis appear in the extracts within the first hour, and the intermediate precursors

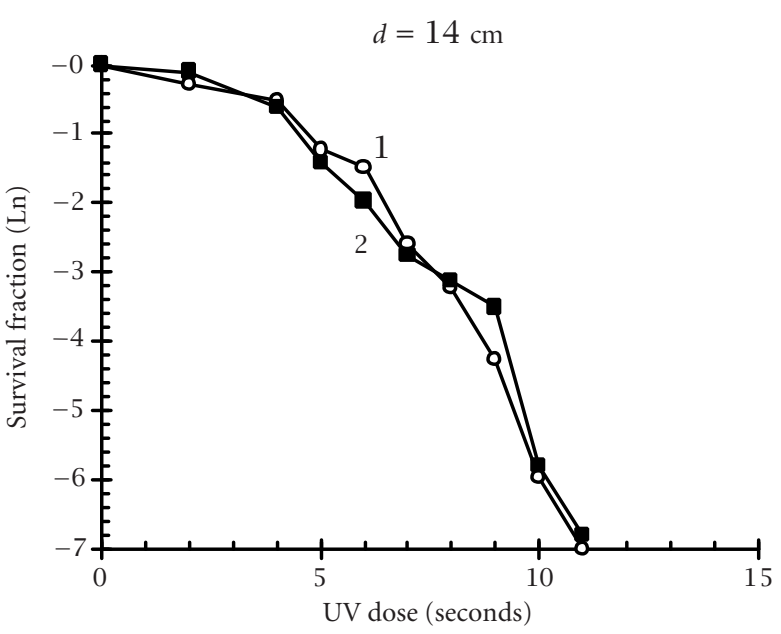

(a)

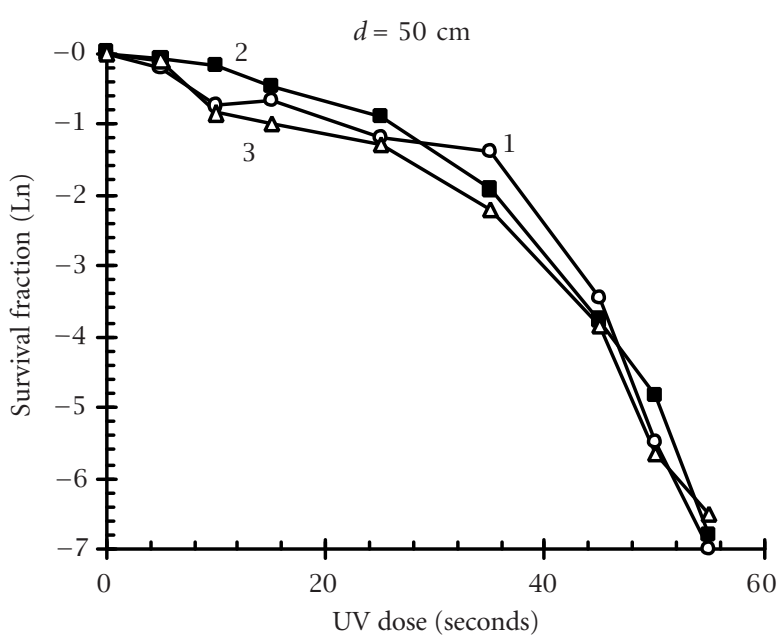

(b)

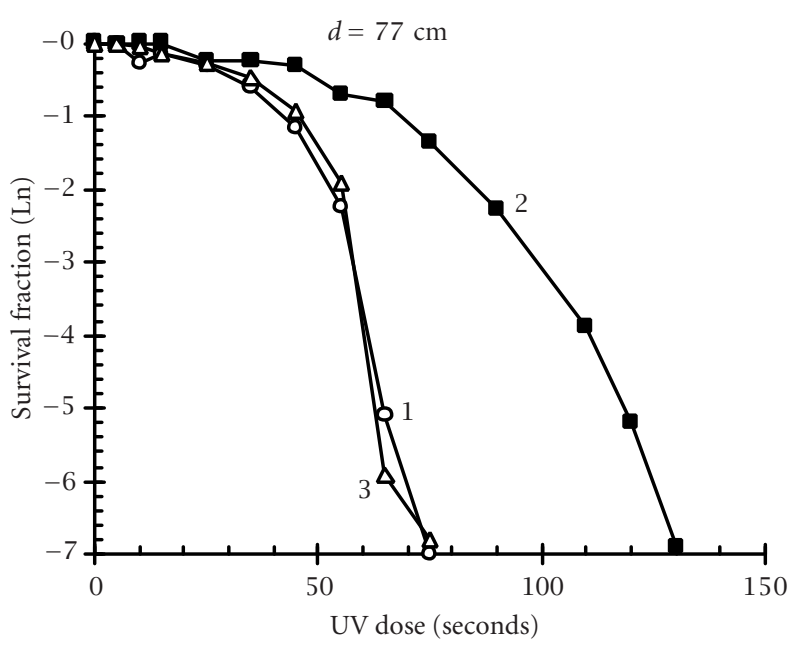

(c)

FIgURE 4: Susceptibility of various E. coli strains to UV radiations. Symbols; 1, E. coli; 2, E. coli containing pC51; 3, E. coli containing pHLD69; d, distance separating the bacterial culture from the UV lamp. 
do not accumulate. This is explained why these intermediates may be difficult to find in bacterial extracts.

Exposure of pigmented strain [E. coli (pC51)] and colorless strains of E. coli [E. coli and E. coli (pHLD69)] to UV light resulted in significant differences in the rate of killing of the colorless strains as compared with the colored strain, which was more resistant to UV radiation (Figure 4). The plasmid pC51, which in addition to pHLD69 vector, contains an insert of $4.42 \mathrm{~kb}$ (Figure 2). Nucleotide sequence analysis of pC1 (see above) reveals that the insert of pC51 only contains the three genes coding for GGPP synthase, phytoene synthase, and phytoene desaturase [6]. This result indicates that the showed differences between E. coli (pC51) and E. coli (pHLD69) (Figure 4, $d=77 \mathrm{~cm}$ ) was due to these genes, which mediate the biogenesis of lycopene in E. coli. Thus, carotenoid pigments are able to diminish the lethal action of UV light. This function can been ascribed to the one or all carotenoids (neurosporene and lycopene) present in extract of $E$. coli carrying pC51. However, the neurosporene was present in too small amounts to be responsible for the showed effect. This is very probably due to lycopene, which is formed in larger quantities (Figure 3). Other scientific data suggest that lycopene may be an important defense mechanism against adverse effects of UV irradiation on the skin [25]. It is now well established that at least some of the adverse effects of UV exposure is mediated by free radicals that can damage (the same as that produced by oxidants of metabolism) to biological molecules, especially to DNA, lipids, and proteins. This damage significantly contributes to the development of degenerative diseases such as cancer, immune-system decline, and cardiovascular disease [26]. Some previous studies showed that lycopene is a potent antioxidant that protects cells against free radicals, and may reduce the risk of chronic diseases such as cancer and coronary heart disease [27-29]. In addition to these therapeutic interests, this carotene can be used equally in food industry as coloring. Lycopene is present in human blood, adipose tissue, adrenals, and testes, its major source for humans being the tomatoes [28]. E. coli containing $\mathrm{pC} 51$ produces a significant quantity of lycopene. This production may improve by transcribing the $\mathrm{pC} 51$ inserted fragment from a strong promoter, and eventually this system could be used as a source of production of this carotenoid.

\section{REFERENCES}

[1] Goodwin TW. The Biochemistry of the Carotenoids. 2nd ed. New York, NY: Chapman Hall; 1980.

[2] Misawa N, Nakagawa M, Kobayashi K, et al. Elucidation of the Erwinia uredovora carotenoid biosynthetic pathway by functional analysis of the gene products expressed in Escherichia coli. J Bacteriol. 1990;172:67046712.

[3] Perry KL, Simonisch TA, Hariston-Lavoie KJ, Liu ST. Cloning and regulation of Erwinia herbicola pigment genes. J Bacteriol. 1986;168:607-612.

[4] Schnurr G, Schmidt A, Sandmann G. Mapping of carotenogenic cluster from Erwinia herbicola and func- tional identification of six genes. FEMS Microbiol Lett. 1991;78:157-162.

[5] Houssaini-Iraqui M, Lazraq R, Clavel-Sérès S, Rastogi N, David HL. Cloning and expression of Mycobacterium aurum carotenogenesis genes in Mycobacterium smegmatis. FEMS Microbiol Lett. 1992;90:239-244.

[6] Viveiros M, Krubasik P, Sandmann G, Houssaïni-Iraqui M. Structural and functional analysis of the gene cluster encoding carotenoid biosynthesis in Mycobacterium aurum $A^{+}$. FEMS Microbiol Lett. 2000;187:95-101.

[7] Cunningham FX Jr, Pogson B, Sun Z, McDonald KA, DellaPenna D, Gantt E. Functional analysis of the beta and epsilon lycopene cyclase enzymes of Arabidopsis reveals a mechanism for control of cyclic carotenoid formation. Plant Cell. 1996;8(9):1613-1626.

[8] Bartley GE, Scolnik PA, Beyer P. Two Arabidopsis thaliana carotene desaturase, phytoene desaturase and zeta-carotene desaturase, expressed in Escherichia coli, catalyse a polycis pathway to yield pro-lycopene. Eur J Biochem. 1999;259(1-2):396-403.

[9] Verdoes JC, Misawa N, van Ooyen AJ. Cloning and characterization of the astaxanthin biosynthetic gene encoding phytoene desaturase of Xantophyllomyces dendrorhous. Biotechnol Bioeng. 1999;63(6):750-755.

[10] Krubasik P, Sandmann G. A carotenogenic gene cluster from Brevibacterium linens with novel lycopene cyclase genes involved in the synthesis of aromatic carotenoids. Mol Gen Genet. 2000;263(3):423-432.

[11] Porter JW, Anderson DG. Biosynthesis of carotenes. Annu Rev Physiol. 1967;18:197-228.

[12] Armstrong GA, Alberti M, Leach F, Hearst JE. Nucleotide sequence, organisation, and nature of the protein products of the carotenoid biosynthesis gene cluster of Rhodobacter capsulatus. Mol Gen Genet. 1989;216:254268.

[13] Chamovitz D, Misawa N, Sandmann G, Hirschberg J. Molecular cloning and expression in Escerichia coli of a cyanobacterial gene coding for phytoene synthase, a carotenoid biosynthesis enzyme. FEBS Lett. 1992;3:305310.

[14] Sandmann G, Misawa N. New functional assignement of carotenogenic genes $\operatorname{crt} B$ and $\operatorname{crt} E$ with constructs of these genes from erwinia species. FEMS Microbiol Lett. 1992;90:253-258.

[15] Sandmann G, Woods WS, Tuveson RW. Identification of carotenoids in Erwinia herbicola and in transformed Escherichia coli strain. FEMS Microbiol Lett. 1990;71:7782.

[16] Sengupta A, Das S. The anti-carcinogenic role of lycopene, abundantly present in tomato. Eur J Cancer. 1999;8(4):325-330.

[17] Bramley PM. Is lycopene beneficial to human health?. Phytochemistry. 2000;54(3):233-236.

[18] Houssaini-Iraqui $M$, Clavel-Sérès S, Rastogi N, David HL. Partial physical and functional map of Mycobacterium aurum carotenogenesis operon. Curr Microbiol. 1993;26:65-74. 
[19] Houssaini-Iraqui M, David HL, Clavel-Sérès S, Hilali F, Rastogi N. Characterization of $\operatorname{car} \alpha$, car Lep and $\operatorname{crt} I$ genes controlling the biosynthesis of carotenes in $M y$ cobacterium aurum. Curr Microbiol. 1993;27:317-322.

[20] Maniatis F, Frisch EF, Sambrook J. Molecular Cloning: A Laboratory Manual. New York, NY: Cold Spring Harbor Laboratory Press; 1982.

[21] Goodwin TW. Carotenoids: Their Comparative Biochemistry. New York, NY: Chemical Publishing Co; 1954.

[22] Fujisaki S, Hara H, Nishimura Y, Horiuchi K, Nishino T. Cloning and nucleotide sequence of isp $A$ gene responsible for farnesyl diphosphate synthase activity in Escerichia coli. Biochem J. 1990;108:995-1000.

[23] Levy-Frébault V, David HL. Mutations affecting carotenoids synthesis in Mycobacterium aurum. J Gen Microbiol. 1979;115:317-327.

[24] David HL. Carotenoid Pigments of the Mycobacteria. The Mycobacteria: a Sourcebook. In: Kupica GP, Wayne LG, eds. New York, NY: Marcel Dekker; 1984; (pt A):537545.
[25] Ribaya-Mercado JD, Garmyn M, Gilchrest BA, Russel RM. Skin lycopene is destroyed preferentially over $\beta$ carotene during ultraviolet irradiation in humans. $J$ Nutr. 1995;125:1854-1859.

[26] Ames BN, Shigenaga MK, Hagen TM. Oxidants, antioxidants, and the degenerative diseases of aging. Proc Natl Acad Sci USA. 1993;90(17):7915-7922.

[27] Clinton SK. Lycopene: chemistry, biology, and implications for human health and disease. Nutrition. 1998;56:35-51.

[28] Gerster H. The potential role of lycopene for human health. J Am Coll Nutr. 1997;16(2):109-126.

[29] Porrini M, Riso P. Lymphocyte lycopene concentration and DNA protection from oxidative damage is increased in women after a short period of tomato consumption. J Nutr. 2000;130:187-192.

* Corresponding author. E-mail: mhi raqui@yahoo.fr

Fax: +212 05 608214; Tel: +21205602953 

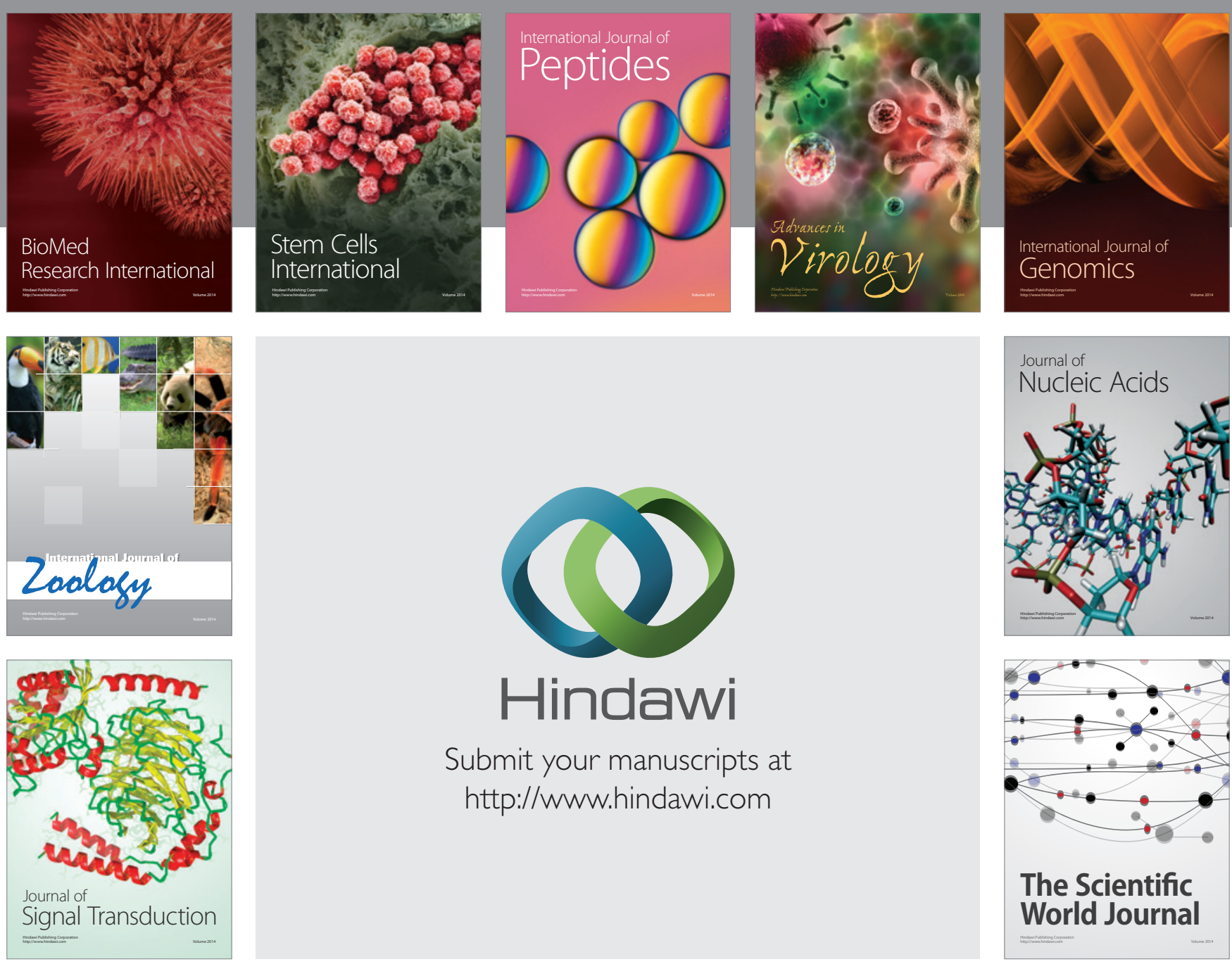

Submit your manuscripts at

http://www.hindawi.com
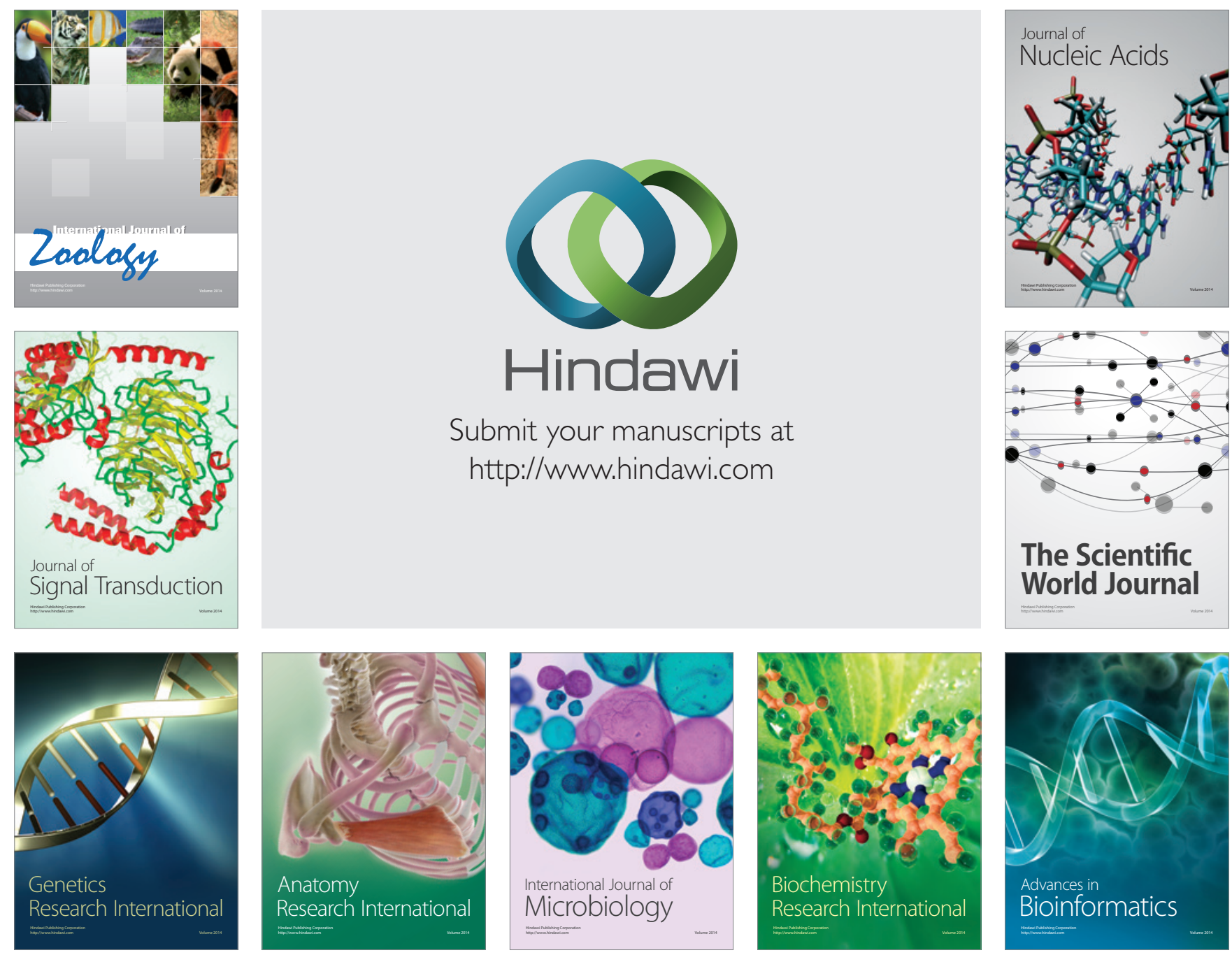

The Scientific World Journal
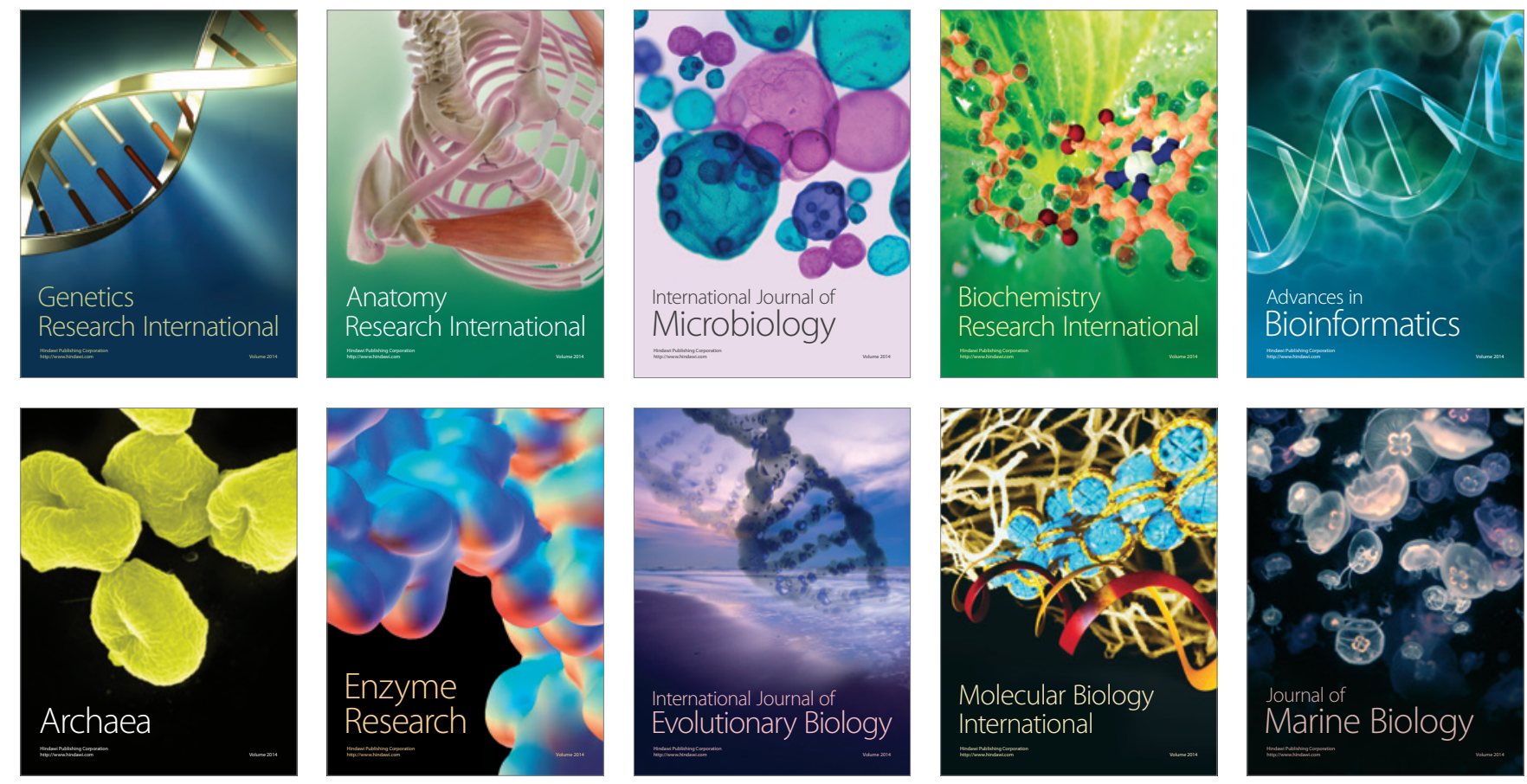